\title{
Factors Contributing To Hospital Readmission In Coronary Care Unit At Assiut University Hospitals.
}

\author{
Mohammed , S ., K ; Ghallab , S ., A; Abdalla , S ., M \& Yussef , H ., R . \\ Head Nurse of Infection Control depar Assuit University Hospital \\ Assist. Prof. of Nursing Administration. Faculty of Nursing- Assuit University
}

\begin{abstract}
Hospital readmissions are believed to be caused by patient frailty and progression of chronic disease. However, from $9 \%$ to $48 \%$ of all readmissions have been judged to be preventable because they were associated with indicators of substandard care during the index hospitalization, such as poor resolution of the main problem, unstable therapy at discharge, and inadequate post discharge care.Aim of the study is; intended to identify factors contributing to hospital readmission, and classify patient's group at high risk of readmission. Design of the study; was descriptive, retrospective and concurrent. Setting; thisstudy was carried out in Coronary Care Unit at Assuit University Hospital. The sample included 76 patients suffering mainly from cardiac disease.

Tools used in this study consist of two parts; first closed chart audit; related to personal characteristics. Second, questionnaire about the reasons of hospital readmission; it included three aspects related to; the hospital, disease, and patients (post care interview). Results;of this study illustrated that most of readmitted patients were male, married, aged from 50 to 64 yearsold, most of them were read \& write and had chronic illness and at the same time did not complied with medication and follow-up appointment. The study concluded that the present study demonstrates highly statistical significant differences between patient's related factors and frequency of readmission among studied patients, and highly statistical significant differences between Recommendation; based on the study findingthe following four strategies recommended reducing hospital readmission as following, screen for patients at risk for readmission, enhance the patient's education program, institute a telephone follow-up program after discharge, and emphasize the importance of data accuracy and integration.
\end{abstract}

\section{Keywords: Hospital Readmission- High Risk Patients}

\section{Introduction:}

Hospitals are faced with an environment of changing policies, resources, and expectations. In recent years the main focus has been upon productivity and cost containment. One of the main challenges facing the hospitals is that the high patient turnover with increasingly shorter stays may affect the quality of care. The care for inpatients and the planning of their discharge must be balanced against the pressure to admit new patients. (TorhildHeggestad, 2002). However, efforts to reduce ICU and CCU utilization and length of stay become more common, it is increasingly important to identify patients at high risk of readmission. Readmission for patients may be a function of their failure to respond to treatment rather than a reflection of poor quality of care or premature discharge. Unplanned readmission is often due to recurrent problems associated with a patient's specific disease and the inherent instability of a severity ill patient. (Weiss man et al, 1999).

While hospital readmission rates have been proposed as an important indicator of quality of care because the readmission may result from action. Also, it is may result from incomplete treatment or poor care of the underlying problem, or may reflect poor coordination of services at the time of discharge and after wards, such as incomplete discharge planning and/ or inadequate access to care. (Friedman et al, 2004 and Mistian et al, 2006).

For most patients who leave the hospital, the last thing they want to return any time soon, yet many medical care patients discharge from an inpatient find themselves back in the hospital within 30 days .Some of these readmission are planned and others may be part of natural course of treatment for specific conditions but increasingly some hospital readmission are being thought avoidable and as indicators of poor care or missed opportunities to better coordinate care (Catlin, et al 2006). Readmission is important not only as quality screens, but also because the readmission is expensive, consuming a disproportionate share of expenditures for inpatient hospital care. (Anderson and Steinberg, 1999, and Kripalani et al, 2007).

Readmission can therefore focus attention on the critical time of an acute illness when the patient is in transition between inpatient and outpatient phases of treatment. To help the prevention of rehospitalization, the health care team needs focus throughout the hospital visit on preparing the patient and caregivers for the transition to home, which these should not occur just moments before discharge. The hospital also needs to coordinate follow up care with primary 
care physicians because when the patients and their caregivers understand the goals of their care, they commonly get better relief from their symptoms and useless health care services at their request (Williams, 2009). Clearly, shortening the lengths of stays and using bed and personnel resources more efficiently are ways to achieve high patient turnover (Torhild Heggestad, 2002).

Significance of the study;

Repeated hospital readmission may demoralize patients and leave them feeling lost and confused. Reducing hospital readmission, represent a unique opportunity for policy makers, payers and providers to reduce health care costs while increasing the quality of care. (Stephen et al, 2009).

The investigator worked as a head nurse at (C.C.U) since 15 years ago noticed that there was a recurrent admission of patients more than 2 times.

It was felt necessary to study this phenomenon in an attempt to identify the factors contributing to hospital readmission, and determine which patients, with different diagnosis are liable for unplanned hospital readmission.

\section{Aims of the study}

This study aimed to;

1- Identify factors contributing to hospital readmission in coronary care unit at Assiut University Hospital

2- Classify patients groups at high risk of readmission in CCU at Assiut University Hospital.

Study Hypotheses;

1- Patients with Chronic illness have higher rates of readmission than who have not.

2- Old age with medical problems have higher rate of readmission than young age without medical problems.

3- Compliance of patients with treatment have lower rate of readmission than non compliant with treatment and follow-up appointment

Subjects \& Methods

The methodology will be portrayed according to four following designs:

1. Technical Design.

2. Administrative Design.

3. Operational Design.

4. Statistical Design.

Technical Design

Include the research design, setting, subject, and data collection

\section{A)Research Design}

This research was descriptive retrospective and concurrent study.

\section{B) Setting}

The present study was conducted in coronary care unit with bed capacity 24 beds at main Assuit
University Hospital. It is providing medical services to all Upper Egypt patients with cardiac disease.

C)Subject

Subjects of the present study include a representative sample $(n=76)$ patients from the total number $(n=450)$ of patients who are readmitted during 6 months from February to July 2009.

D) Data collection Tools;

A structured checklist and interview questionnaire for patients developed by (Anderson etal, 1996) and modified by Panel Team, (1997) consists of 2 parts; Part 1 ; Closed chart audit; related to personal characteristics of patient's data include, patient's age ,sex, marital status, educational level, occupation and social \&financial status.

Part 2; Questionnaire about the reasons of hospital readmission; it consists of 3 aspects related to; Hospital, Disease and Patients (post care interview), presented as the following;

Aspect related to hospital; this aspect consists of 3 items;

a-Types of hospital(teaching hospital, privet hospital or all of them),scoring ranged from one for teaching hospital, two for privet hospital and three for all of these.

b-When patients prepared for discharge ;( during hospitalization, at the moment of discharge or both) scoring ranged from one during hospitalization to three for both.

C-Presence of rehabilitation program (yes or no) scoring ranged from one for no and two for yes.

Aspect related to disease; was consists of 2 parts;

Part I-include four items;

1- Presence of chronic disease or not.

2- Patient careful to make follow-up for this chronic disease or not.

3- Compliance with medication of chronic disease and

4- Presence of unresolved medical problem before discharge.

Scoring for this items were 2 for yes and one for no.

Part II- includes patient's diagnosis (multisystem failure) which consists of 4 system disorders (Central nervous system disorder, Circulatory disorder, Respiratory system disorder, and digestive system disorder). Scoring ranged from one for (CNS) disorder to 4 for digestive system disorder respectively.

Aspect related to patients; consists of 3 items;

1- Presence of care provider after discharge (self care, spouse, relative or friend-or paid help) scoring ranged from one for self care to 4 for paid help respectively.

2- Patient's compliance for medications (yes or no), scoring ranged from one for no to two for yes and if answer with no then another 4 
choices given to the patient to determine which of them was the main cause for non-compliance with medications. These choices were; "low socio-economic level, there is no outside financial support, negligence from the patient himself, and patient's ignorance by the nature of his disease" Scoring ranged from one to four for every choice respectively.

3- Social \& financial support for the patient after discharge, this item includes 4 choices as following; A- Personal financial support, BHealth insurance, C- Government financial support, and D- University staff member. Scoring for this item ranged from one to four for every option respectively.

2- Administrative design

An official permission had been obtained to collect the necessary data from administrative persons at main A.U.H

* Ethical consideration;

* Oral consent was taken from the patients who are readmitted to fulfill the necessary data needed.

* Coding of data was made by the researcher to maintain the privacy and confidentiality of patient's data.

3- Operational Design:

A) Preparatory phase.

This phase took about one month from January (2009) to the end of the same month for reviewing the available literatures.

B) Data collection:

After obtaining verbal consent from patient, the data collected was done through structured interview questionnaire with patients who readmitted to fill the necessary data in the form .This took about an hour for each patient in the study, the duration took about 6 month from February to July (2009) .

\section{4- Statistical Design:}

Data entry and analysis were done using SPSS version 12(statistical package for social science). Data were presented using descriptive statistics in the form of frequencies and percentages, mean, and standard deviations.

- Limitation of this study;

1-The sample size was small and the study was carried out in only one setting due to shortage in documentation and records in the other two unitgeneral medicine department and general out patient department in the same hospital.

2-Some of studied patients missed from sample due to discharged of those patients on demands at the same day of admission, so the researcher can not collect needed data.

\section{Results:}

Table (1) described patient's related factors for hospital readmission, It showed that above two third of them were male and aged above 50 years to under 79 years old $(40.78 \%, 34.22 \%)$ respectively. The majority of them were married $(82.09 \%)$, about one third of them read \& write and illiterate $(39.48 \%$, $38.16 \%$ ) respectively, Fifty percent of them employed in governmental agencies and less than half of them receiving financial support from health insurance and more than half of them were cared after discharge by themselves and others.

Table (2) Regarding to patient's compliance/ non compliance with medical treatment, it is reveals that above half of them were complied with treatment $(53.95 \%)$ and less than half of them were non complied $(46.05 \%)$ for the following causes, low socio-economic status, patient's negligence, no external support $(26.31 \%, 13.16 \%, 6.58 \%)$ respectively.

Table (3) describes disease-related factors among studied patients, It showed that above two third of them were had chronic diseases $(73.69 \%)$, more than fifty percent of them were complied with medication of chronic diseases $(53.95 \%)$, less than fifty percent of them were complied with follow-up and treatment of chronic diseases $(42.11 \%)$ and minority of them $(7.89 \%)$ were had unresolved medical problem before discharge.

Regarding to second part of disease- related factors, (patient's diagnosis), the majority of patients complained from circulatory system disorder , followed by central nervous system disorder, respiratory system disorder, and finally digestive system disorder $(98.68 \%, 88.16 \%, 76.32 \%, 65.78 \%)$ respectively.

Table (4) Shows system-related factors, above two third of them were readmitted in university hospital, while below one quarter of them $(72.95 \%)$ readmitted in governmental hospital and private hospital $(13.89 \%, 13.16 \%)$ respectively.

Regarding to the time of preparing patient for discharge, two third of them were prepared on discharge(at the moment of discharge) $(60.53 \%)$, while few percent of them (10.53\%)were prepared during hospitalization, followed by less than one third of them prepared on discharge and during hospitalization together (28.95\%).

Regarding to patients rehabilitation before discharge, above two third of them did not receive any rehabilitation before discharge $(64.47 \%)$, while above one third of them were received rehabilitation before discharge $(35.53 \%)$.

Table (5) Clarify patients groups at high risk of readmission, it shows that, most of studied patients 
have the same characteristics as most of them were male, married, aged from 50 to 64 years old, read \& write and illiterate, work at governmental agencies and had health insurance.

Table (6) describes the relationship between patient's related factors and frequency of readmission; it was found that a highly statistical significance differences between patient's related factors and frequency of readmission $\mathrm{P}(<0.001)$.

Table (7) described the relationship between diseaserelated factors and frequency of readmission, It was found that no statistical significance differences between presence of chronic disease and frequency of readmission among studied patients, $\mathrm{P}(<0.0157)$, while there was highly statistical significance differences between follow-up \& treatment of chronic disease and compliance with medication.

Table (8) clarified the relationship between systemrelated issues and frequency of readmission among studied patients, It was found that a highly statistical significance differences between system-related factors and frequency of readmission, p $(<0.001)$

Table (1): Patient's personal characteristics among readmitted patients in $\mathrm{CCU}(\mathrm{n}=76)$.

\begin{tabular}{|c|c|c|}
\hline Patient's related factors & No & $\%$ \\
\hline $\begin{array}{l}\text { 1-Sex } \\
\quad * \text { Male } \\
\quad * \text { Female }\end{array}$ & $\begin{array}{l}51 \\
25\end{array}$ & $\begin{array}{l}67.02 \\
32.08\end{array}$ \\
\hline $\begin{array}{l}\text { 2- Age(in years) } \\
\text { * From } 35-49 \text { years } \\
\text { * From } 50-64 \text { years } \\
\text { * From } 65-79 \text { years } \\
\text { * Up to } 80 \text { years } \\
\end{array}$ & $\begin{array}{c}17 \\
31 \\
26 \\
2 \\
\end{array}$ & $\begin{array}{c}22.37 \\
40.78 \\
34.22 \\
2.63\end{array}$ \\
\hline $\begin{array}{l}\text { 3- Marital status } \\
\text { * Single } \\
\text { * Married } \\
\text { * Widow } \\
\end{array}$ & $\begin{array}{c}6 \\
63 \\
7 \\
\end{array}$ & $\begin{array}{c}7.89 \\
82.09 \\
9.21 \\
\end{array}$ \\
\hline $\begin{array}{l}\text { 4- Educational level } \\
\text { * Illiterate } \\
\text { * Read \& write } \\
\text { * University graduate } \\
\text { * Post graduate } \\
\end{array}$ & $\begin{array}{c}29 \\
30 \\
10 \\
7 \\
\end{array}$ & $\begin{array}{l}38.16 \\
39.48 \\
15.03 \\
7.33\end{array}$ \\
\hline $\begin{array}{l}\text { 5- Occupation } \\
\text { * No work } \\
\text { * Skilled work } \\
\quad * \text { Employee (government agencies) } \\
\quad * \text { Employee (private agencies) } \\
\end{array}$ & $\begin{array}{c}30 \\
4 \\
38 \\
4 \\
\end{array}$ & $\begin{array}{c}39.56 \\
5.22 \\
50 \\
5.22 \\
\end{array}$ \\
\hline $\begin{array}{l}\text { 6- Financial support } \\
\quad * \text { Personal } \\
\quad * \text { Heath insurance } \\
\quad * \text { Faculty member } \\
\quad * \text { Governmental support (Free-support) }\end{array}$ & $\begin{array}{c}22 \\
35 \\
4 \\
15 \\
\end{array}$ & $\begin{array}{c}28.95 \\
46.08 \\
5.22 \\
19.75 \\
\end{array}$ \\
\hline $\begin{array}{l}\text { 7- Care provider after discharge } \\
\text { * By himself } \\
\text { * By others } \\
* \text { Both(by pt. and others) }\end{array}$ & $\begin{array}{c}8 \\
27 \\
41\end{array}$ & $\begin{array}{l}10.12 \\
35.83 \\
54.05\end{array}$ \\
\hline
\end{tabular}

Table (2): Number and percentage of compliance / non compliance with treatment among hospital readmitted patients in C.C.U (n=76)

\begin{tabular}{|l|l|l|l|l|l|}
\hline Compliance & NO & \% & Non compliance & NO & \% \\
\hline & 41 & $53.95 \%$ & Related causes & 35 & 46.05 \\
\hline & & & 1- low socio-economic level & 20 & 26.31 \\
\hline & & & 2- No external support & 5 & 6.58 \\
\hline & & & 3- patient's negligence & 10 & 13.16 \\
\hline & & & 4- patient unaware the nature ofdisease & 0 & 0 \\
\hline
\end{tabular}


Table (3): Number and percentage of disease related factors among hospital readmitted patients in C.C.U ( $n=76)$

\begin{tabular}{|l|c|c|}
\hline Disease-related factors & No & $\%$ \\
\hline (-chronic diseases) & & \\
\hline 1- Presence of chronic diseases & 56 & 73.69 \\
\hline 2- Follow - up \& treatment of chronic diseases & 32 & 42.11 \\
\hline 3- Compliance with medication of chronic diseases & 41 & 53.95 \\
\hline 4- Presence of unresolved medical problem before discharge & 6 & 7.89 \\
\hline - patient's diagnosis & & 98.68 \\
\hline 1- Circulatory system disorder & 74 & 88.16 \\
\hline 2- Central Nervous system disorder & 24 & 76.32 \\
\hline 3- Respiratory system disorder & 20 & 65.78 \\
\hline 4- Digestive system disorder & 12 & 2 \\
\hline
\end{tabular}

Table (4): Number and percentage of system related factors among hospital readmitted patients in C.C.U ( $n=76)$

\begin{tabular}{|l|c|c|}
\hline System-related factors & No & \% \\
\hline 1- Types of hospital & & 13.89 \\
* Govern hospital & 16 & 72.95 \\
* University(teaching) hospital & 50 & 13.16 \\
* Private hospital & 10 & 10.53 \\
\hline 2- Time of preparing patient for discharge & & 60.53 \\
* During hospitalization & 8 & 28.95 \\
* On discharge & 46 & 35.53 \\
* Both of them & 22 & 64.47 \\
\hline 3- Rehabilitation before discharge & & 27 \\
* Done & 49 & \\
* Not done & & \\
\hline
\end{tabular}

Table (5): Patient's demographic factors and care provider and frequency of readmission inCCU at A.U.H

\begin{tabular}{|l|c|c|}
\hline \multirow{2}{*}{ Factor related to hospital readmission } & \multicolumn{2}{|c|}{ Frequency of readmission } \\
\cline { 2 - 3 } & 2 times & 3 times or more \\
\hline 1- Age Factor & & 14.47 \\
- > 50 years & 10.54 & 26.32 \\
- 50 - 65 years & 14.47 & 14.47 \\
- - to 65 years & 19.73 & 63.85 \\
\hline 2- Gender factor & & 18.42 \\
- Male & 30.26 & 15.78 \\
- Female & 14.47 & 26.32 \\
\hline 3- Education factor & & 13.17 \\
- Illiterate & 22.36 & 19.74 \\
- Read \& Write & 13.15 & 1.32 \\
- University & 9.22 & 30.26 \\
\hline 4- Occupation factor & & 3.94 \\
- No work & 19.74 & \\
- Skilled work & 3.94 & 5.26 \\
- Employee (government) & 19.74 & 42.11 \\
- Employee (private) & 1.32 & 7.89 \\
\hline 5- Marital status factor & & \\
- Single & 2.64 & \\
- Married & 40.78 & \\
- Widow & 1.32 & \\
\hline
\end{tabular}




\begin{tabular}{|l|c|c|}
\hline \multirow{2}{*}{ Factor related to hospital readmission } & \multicolumn{2}{|c|}{ Frequency of readmission } \\
\cline { 2 - 3 } & 2 times & 3 times or more \\
\hline 6- Financial factor & & 9.21 \\
- Personal & 19.73 & 28.94 \\
- Health insurance & 17.11 & 2.63 \\
- University & 2.64 & 14.47 \\
- Governmental & 5.27 & 7.89 \\
\hline 7- Care provider after discharge factor & & 17.11 \\
- By himself & 2.63 & 30.26 \\
- By others & 18.43 & 23.68 \\
- Both & & \\
\hline
\end{tabular}

Table (6) Relationship between patient's related factors and frequency of readmission at C.C.U among hospital readmitted patients $(n=76)$ :

\begin{tabular}{|c|c|c|c|c|}
\hline \multirow[t]{2}{*}{ Patient's related factors } & \multicolumn{2}{|c|}{ Frequency of readmission } & \multirow[t]{2}{*}{$\mathbf{C H} \times 2$} & \multirow[t]{2}{*}{ P value } \\
\hline & 2 times & 3 times or more & & \\
\hline $\begin{array}{l}\text { 1- Age factor } \\
>50 \text { years } \\
-50-65 \text { years } \\
<65 \text { years }\end{array}$ & $\begin{array}{l}10.54 \\
14.47 \\
19.73\end{array}$ & $\begin{array}{l}14.47 \\
26.32 \\
14.47\end{array}$ & 25.6 & $<0.001$ \\
\hline $\begin{array}{l}\text { 2- Gender factor } \\
\text { - Male } \\
\text { - Female }\end{array}$ & $\begin{array}{l}30.26 \\
14.47\end{array}$ & $\begin{array}{l}63.85 \\
18.42\end{array}$ & 23.75 & $<0.001$ \\
\hline $\begin{array}{l}\text { 3- Education factor } \\
\text { - Illiterate } \\
\text { - Read and write } \\
\text { - University }\end{array}$ & $\begin{array}{c}22.36 \\
13.15 \\
9.22\end{array}$ & $\begin{array}{l}15.78 \\
26.32 \\
13.17\end{array}$ & 23.23 & $<0.001$ \\
\hline $\begin{array}{l}\text { 4- Occupation factor } \\
\text { - No work } \\
\text { - Skilled work } \\
\text { - Employee (government) } \\
\text { - Employee (privet) }\end{array}$ & $\begin{array}{c}19.74 \\
3.94 \\
19.74 \\
1.32\end{array}$ & $\begin{array}{c}19.74 \\
1.32 \\
30.26 \\
3.94\end{array}$ & & \\
\hline $\begin{array}{l}\text { 5- Marital status factor } \\
\text { - Single } \\
\text { - Married } \\
\text { - Widow }\end{array}$ & $\begin{array}{c}2.64 \\
40.78 \\
1.32\end{array}$ & $\begin{array}{c}5.26 \\
42.11 \\
7.89\end{array}$ & 21.23 & $<0.001$ \\
\hline $\begin{array}{l}\text { 6- Financial factor } \\
\text { - Personal } \\
\text { - Health insurance } \\
\text { - University } \\
\text { - Governmental }\end{array}$ & $\begin{array}{l}19.73 \\
17.11 \\
2.64 \\
5.27\end{array}$ & $\begin{array}{c}9.21 \\
28.94 \\
2.63 \\
14.47\end{array}$ & 21.20 & $<0.001$ \\
\hline $\begin{array}{l}\text { 7- Care provider after dischar } \\
\text { factor } \\
\text { - By himself } \\
\text { - By others } \\
\text { - Both }\end{array}$ & $\begin{array}{c}2.63 \\
18.43 \\
23.68\end{array}$ & $\begin{array}{c}7.89 \\
17.11 \\
30.26\end{array}$ & 24.21 & $<0.001$ \\
\hline
\end{tabular}


Table (7) Relationship between diseases related factors and frequency of readmission at C.C.U among hospital readmitted patients $(\mathbf{n}=76)$.

\begin{tabular}{|c|c|c|c|c|c|c|}
\hline \multirow{3}{*}{ Disease -related factors } & \multicolumn{4}{|c|}{ Frequency of readmission } & \multirow{3}{*}{$\mathbf{C H} \times 2$} & \multirow{3}{*}{$P$ value } \\
\hline & \multicolumn{2}{|c|}{2 times of only } & \multicolumn{2}{|c|}{ 3times or more } & & \\
\hline & No & $\%$ & No & $\%$ & & \\
\hline 1- Presence of chronic disease & 12 & 15.78 & 20 & 26.32 & 2 & $<0.157$ \\
\hline $\begin{array}{l}\text { 2- Follow-up \& treatment of } \\
\text { chronic disease }\end{array}$ & 6 & 7.89 & 15 & 19.74 & 3.857 & $<0.0495$ \\
\hline $\begin{array}{l}\text { 3-Compliance with medication of } \\
\text { chronic disease }\end{array}$ & 5 & 6.58 & 15 & 19.74 & 5 & $<0.025$ \\
\hline $\begin{array}{l}\text { 4-Presence of unresolved medical } \\
\text { problem before discharge }\end{array}$ & 0 & 0.00 & 3 & 3.95 & - & - \\
\hline
\end{tabular}

Table (8): Relationship between system-related factors and frequency of patients' readmission among studied patients:

\begin{tabular}{|c|c|c|c|c|c|c|}
\hline \multirow{3}{*}{ System -related factors } & \multicolumn{4}{|c|}{ Frequency of readmission } & \multirow{3}{*}{$\mathbf{C H} \times 2$} & \multirow{3}{*}{$P$ value } \\
\hline & \multicolumn{2}{|c|}{2 times of only } & \multicolumn{2}{|c|}{ 3times or more } & & \\
\hline & No & $\%$ & No & $\%$ & & \\
\hline $\begin{array}{l}\text { 1- Types of hospital } \\
\text { - Governmental hospital } \\
\text { ( University \& teaching ) }\end{array}$ & 30 & 39.47 & 36 & 47.38 & 23.23 & $<0.001$ \\
\hline - private hospital & 4 & 5.26 & 6 & 7.89 & 23.23 & $<0.001$ \\
\hline $\begin{array}{r}\text { 2- Time of preparing fordischarge } \\
\text { - During hospit }\end{array}$ & 0 & 0.00 & 8 & 10.53 & & $<0.001$ \\
\hline - On discharge & 26 & 34.21 & 20 & 26.31 & 25.6 & $<0.001$ \\
\hline - Both & 8 & 10.53 & 14 & 18.42 & & \\
\hline $\begin{array}{l}\text { 3- Rehabilitation before discharge } \\
\text { - Done }\end{array}$ & 9 & 11.85 & 18 & 23.68 & 23.75 & $<0.001$ \\
\hline - Not done & 25 & 32.89 & 24 & 31.58 & & $<0.001$ \\
\hline
\end{tabular}

\section{Discussion:}

Hospital readmission associated with indicators of substandard care during the index hospitalization, such as poor resolution of the main problem, unstable therapy at discharge, and inadequate post discharge care. However, hospital readmissions are costly to hospitals and to patients, accounting for up to half of all hospitalization $(60 \%)$ of hospital costs. Beside the expense, readmission may reflect poor quality care. Determining what factors are related to unplanned readmission may lead to finding specific causes or trends that can be addressed by management. Once causes are known, solutions can be recommended to management and implemented to reduce readmission rates, benefiting both the hospital and patients. (Weinberger andOddone, 1996). The current study was conducted with the aim to identify the factors contributing to hospital readmission and classify patients groups at high risk of readmission in C.C.U at A.U.H.

The overall findings of this study are consistent with other studies conducted locally and overseas.
This study, however, included multiple factors (demographic variables, health assessment, medical diagnosis, frequency of admissions, and socioenviromental variables).

Regarding to patient's related factors(patient's gender) as a contributing to readmission (table 1) the findings depicted that, the majority of study subjects were males, this findings was supported by Kossovesky et al, (1999) and Mark et al, (2007), who found that the probability of being readmitted is higher among men than women. And was in contrast with the findings of Mosca et al,(2007) found that the most readmitted patients were females patients with limited capacity for health care decision making and self care.

Regarding to the patient's age, the findings of this study revealed that the majority of patients aged from 50 to 64 years old and about one third of them more than 65 years. This findings were consistent with the findings of Billings et al,(2006); Silverstein et al,(2008)and Howell et al,(2009) have shown that the patients who were under 65 years had a slightly 
higher probability of being readmitted than those who were above 65 years old. While Donnan et al, (2008) and Howell et al, (2009) in their studies found that age did not related to hospital readmission.

Regarding to the marital status, the present study showed that up to two third of patients were married. This finding is running with Winslow, (2001); Qieu et al, (2001); who found that married patients under stressful situations had higher rate of heart attacks and hospital readmission.

About the educational level, up to one third of patients was read\&write and illiterate, this might be due to that patients who are highly educated, can cope with stressful situations positively and can manage their problems effectively than illiterate patients .Beside that, highly educated patients can manage their disease effectively by compliance with health care instructions (food consuming, performance of exercise, smoking, and facing of daily problems). These findings supported by the study findings of Winslow, (2001) who found that illiterate patients more liable to had recurrent admission due to lack of knowledge and self care.

Regarding to the occupation and financial support studied patients denoted that half of them who were working at governmental agencies had higher rate of unplanned readmission, this results might be due to patient's perception that those agencies will cover their admission and their treatment (benefits of health insurance). While patients who did not work at governmental agencies, seems anxious due to low income, cost of hospital admission and treatment and absence of financial support.

Rubenach, (2002) found that social support plays an important role in the onset of disease and recovery process, especially after heart attacks. On the other hand, social support has a major benefit in handling stressful events with respect to cardiac health. Moreover, social support influences quality of life in coronary artery disease patients. But there is one study done in California by Howell, (2009) who found that patients with private insurance had lower rate of readmission and paid less for their initial admission stay because readmission is expensive for them and for caregivers.

Regarding to the care providers after discharge, the findings of the present study declared that, up to half of patients had care providers after discharge such as family members, relatives or paid help or by patient himself had higher rate of hospital readmission while for the patients who cared by others only, were up to one third of patients readmitted this findings might be attributed to that care providers not available all the times so the patients receive interrupted care.
This findings table(1) were in converse with the study findings of Billings et al, (2006); Donnan et al, (2008); and Howell et al, (2009) who found that patients who receives home care services that monitoring patient's condition, medication compliance and nutrition were less likely experience hospital readmission than who did not have home care services.

Regarding to the patient's compliance and non compliance with treatment, the findings of the present study showed that, aboutmore half of them were complied with treatment while below half of them were not complied for the following causes," low socio-economic status, patient's negligence and no external financial support while it was noticed that, patients who had enough financial support and health insurance were complied than patients who did not have health insurance or financial support.

The findings of table( 2) were inconsistent with the findings of Hurst's ,(2005) who found that, only about $12 \%$ of readmitted patients were not complied with treatment due to lack of follow-up care coordination or behavioral choices such as non compliance with dietary recommendations, medication and life style pattern changing.

Disease-related factors, as a contributing factor of hospital readmission, the findings of the current study revealed that, above two third of patients had chronic diseases, above fifty percent of them were complied with medication of chronic diseases, while less than fifty percent of them were complied with follow-up and treatment of chronic disease.

These findings in the same line with studies done by Department of Health, (2005) which stated that, chronic diseases were considered a best indicator for hospital readmission because patients with chronic medical conditions tend to experience frequent hospitalization.

Regarding to patient's diagnosis, as a predisposing factor of readmission, the majority of patients diagnosed in the following order, firstly circulatory system disorders followed by central nervous system disorders, then respiratory system disorders, and finally digestive system disorders.

This findings supported by the study findings of Ross et al, (2008) who found that the hospital readmission happened for the same sequence of patient's diagnosis ranking. Meanwhile, did not supported by the findings of Howard et al, (2008) who stated that, the order ofthe diseases category varies, as the respiratory problems occupy the top of three conditions that require hospital readmission.

Regarding to the system related factors as a contributing factor of hospital readmission, the findings of the present study depicted that, above two third of patients were readmitted in university 
hospital, below one quarter of them readmitted in governmental hospital and private hospital. This may be due to availability of high technology of medical services, and availability of qualifiedmedical and nursing staff.

This findings in accordance with the study of Fernandes, (2003)) who showed that, teaching hospital and hospital with less than 100 beds tend to have higher readmission rate and is actually inefficient and associated with increased length of hospital stay and readmission.

Regarding to the time of preparing patient for discharge, the findings of the present study clarified that, about two third of them were prepared (on the day of discharge), while the minority of them were prepared during hospitalization. This may be due to shortage of medical and nursing staff, and lack of time needed for preparation, or may be due to bad system.

These findings were on the same line with the findings of (Richardson, 2006) who found that, patients teaching for discharge are usually done in a single sitting on the day of discharge; this does not allow enough time for patients and their caregivers to learn all of the health maintenance information needed to prevent rehospitalization.

Regarding to the rehabilitation before discharge, the findings of the present study denoted that, above two third of them did not receive any rehabilitation before discharge again this may be due to lack of medical and nursing staff. These findings were also supported by Horgan et al, (1995) who stated that, post discharge rehabilitation in some developed countries until recently include no more than one page of written advice about the discharge instructions.

According to Silverstein,(2008) cardiac rehabilitation is part of the long term comprehensive care of cardiac patients, it should be include both an individualized regimen of physical activity and health education as appropriate for the patient's needs. Also its benefits of improve physical function, health status, improve quality of life, increase social independence and decrease hospital readmission.

Regards to the relationship between patient's related factors and frequency of hospital readmission, it was found a highly statistical significant difference among studied patients. This might be due to that most of studied patients have the same characteristics as most of them were males, aged from 50 to 64 years old, married, read\& write and illiterate, work at governmental agencies, and had health insurance . Relationship between disease-related factors and frequency of hospital readmission, it was revealed that highly statistical significant differences among studied patients table (7). This might be due to that most of them were similar in the following properties presence of chronic diseases, compliance with medication and follow-up appointment.

Regarding to relationship between system-related factors and frequency of hospital readmissions, it demonstrated highly statistical significant differences among studied patientstable (8). This result might be due to that similarity of patients in the following characteristics" most of them readmitted at university hospital, prepared for discharge on the day of leaving the hospital, most of them did not receive rehabilitation program and have the same perception about the causes of hospital readmission from their point of views.

\section{Conclusion:}

The results obtained from this study concluded that the most readmitted patients were males, married, aged from 50 to 64 years old, most of them were read \&write and had chronic illness and at the same time were not complied with medication or follow-up appointment due to low socio-economic status and for some patient due to patient's negligence or due to absence of external financial support. Also the present study demonstrates that highly statistical significant differences between patient's related factors and frequency of readmission among studied patients, and highly statistical significant differences between system-related issues and frequency of readmission. Regarding to the reasons of hospital readmission as perceived by patients, there were a highly statistical significant difference between patient's reasons of hospital readmission and frequency of readmission.

\section{Recommendations:}

Consequently and based upon such results, the recommendations of this study will cover a 4 main strategies for improvement stated as the following; 1Screen for patients at risk for readmission through;

- Social workers and discharge planners.

- Also nurses can screen for high risk patients when assessing patients at admission during subsequent daily assessment.

- The screening tool could be a simple questionnaire. Any patient who has more than 3 positive responses to these questions will be considered at high risk for readmission.

The recommended screening tool may include the following;

1 - Is the patient more than 65 years old?

2- Does the patient have chronic illness (heart disease, lung disease, DM, or gastrointestinal disease) 
3- Does the patient have anyone to help at home after discharge?

4- Has the patient been hospitalized one or more times in the past twelve months?

5-Has the patient seen a doctor more than six times in the past twelve months?

6-Does the patient have a history of depression or mental status changes within the past two months?

7-Has the patient experienced a decline in physical health and activity within the past two months?

2-Enhance the patient's education programthrough the following approaches ;

- Clear and simple discharge planning instructions.

- Classes about lifestyle changes including, diet, exercise, medications, and hygiene.

- Group therapy for patients to give each patient the opportunity to discuss their experience with their illness especially those compliant patients to encourage other patients to manage their illness effectively.

- Attending of new nurses for workshop about discharge plan and how they should be effective part in formulating discharge plan.

3-Institute a Telephone Follow-up program After Discharge through;

- Qualified and well trained nurses to response with patients through telephone to clarify for the patients any information about diet, activity, and any other health related issues.

- Review of follow-up appointment card for dates and time of follow-up visits.

- Inform the patients about any signs or symptoms should be reported to the doctor or a nurse through calls.

4-Emphasize the importance of data accuracy and integrity through

- Keep data input into the data base.

\section{References:}

1. A pilot study. Journal of Community Health Nursing, 45(3), p.p. 1-12

2. Anderson, G.F\& Steinberg, E.P. (1999): Hospital readmission in the Medicare population. The New England Journal of Medicare, 10 (4), P.p. 311, 1349, 1353.

3. Anderson, M.A., Hanson, K.S\& DeLilder, N.W (1996): Hospital Readmission during home care;

4. Billings $\mathbf{S}$, (2006): Why are elderly individuals at risk of hospital readmission? Journal of Nursing Association; 10 (3), P.p. 25-29.

5. Catlin, A. (2006): National Health spending in 2006; a year of change for prescription drugs, 27 (1), P.p. 14-29.
6. Department of Health, (2005): Supporting people with long term conditions: on NHS and Social care model to support local innovation and integration. London: Department of Health, 2005 (available at, www.dh.gov. uk/asset Root/04/09/98/68/0499868.pdf).

7. Donald, P.T., Dorward, B, Mutch and A.D. Morris (2007): Development and Validation of a Model for Predicting EmergencyAdmission over the Next year; American Heart Association 168 (13), P.p. 1416- 1422

8. Fernandes, S.L., (2003): Hospital Readmission in teaching hospitals and its impact on medical care. Health Policy 44 (2), p.p. 150-158

9. Friedman, B, and Basu, J (2004): The rate and Cost of Hospital Readmission for preventable conditions. Journal of Geriatric Drug Therapy; 28 (10) P.p. $225-240$.

10. Horgan J., McGee, $H$ and Jones, R, (1995): Cardiac rehabilitation: future directions in cardiac rehabilitation. London; BMJ publishing.3 (115) P.p. 244-256.

11. Howell S., (2009): Lifestyle and indoor of hospital readmission. The impact of readmission on patient moral, Seminar in Oncology Nursing, The American Journal of Managed Care 36(3), P.p. 547-463.

12. Hurt S, Robert $A$, and O'Rourke Fuster, (2005): Manual of Cardiology. By the McGrawHill Companies. Vol (55) No 8 P.p. 280-284.

13. Kossovesky, M.P, Permeger, T.V, Sarasin, F.P., Bolla, F., \& Gaspoz, J (1999): Comparison between planned and unplanned readmission to a department of internal medicine, Journal of Clinical epidemiology 17 (5) P.p. 122- 130.

14. Kripalani, S (2007): Promoting effective transition of care at hospital discharge: A Review of Key Issues for Hospitalists; Journal of hospital Medicine, 2 (5), September/ October, 2007, P.p. 314- 323

15. Mark, D.B., and Hlatky, M.A. (2007): Medical Economics and the Assessment of value in cardiovascular Medicine: part2 .circulation, 88 (15) P.p. 106:626-630(Full Text)

16. Mistian P, Poot E. (2006): telephone follow-up initiated by a hospital based health professional for post discharge problems in patients discharged from hospital to home. Cochrane Data base system Rev (Pub Med), 108(26), P.p. 445-450.

17. Mosca L, Banka C, and Benjamin E, (2007): Evidence -Based Guidelines for Cardiovascular Disease Prevention in women. Update Circulation. Published online February 2007; 17(2), P.p. 150- 171. 
18. OddoneE,\& WeinbergerM. (1996): Strategies to reduce hospital readmission,New England Journal of Medicine. 8 (5) P.p. 255-260

19. Panel Team (1997): Improving Hong Kong health care system (main report and special reports) in Hong Kong Regional Hospital.

20. Phillips C, Wright $S$, Kern $D$ and Singa $R$, (2004): Comprehensive discharge planning with post dischargesupport for olderpatients with CHF: a meta analysis. JAMA 2004; 11(5), P.p. 291-298.

21. Qiue C, Backman L, and Winblad, B. (2001): The influence of education on hospital readmission. Htt: //biology.

22. Richardson E., (2006): Interventions to improve access to health and social care after discharge from hospital: j Am Acad Nurse Pract. 44(5), P.p. 145-150.

23. Ross, J.S., Mulvey, G.K., Stauffer, B, Patolla, V., Bernheim, S., M., Keenan, P.S., (2008): Statistical Models and patient Predictors of Readmission for Heart Failure" Archives of Internal Medicine P.p. 168- 173.

24. Rubenach S, Shdbolt B, and McCallum J, (2002): Assessing health-related quality of life following cardiac attacks.Journal of General Internal Medicine33(4), P.p. 99-105.

25. Silverstein L, and Sullivan D., (2008): Risk factors for early hospital readmission in a selected population of geriatric rehabilitation. Jam Geriatric Sac 18 (5), P.p. 171- 175.

26. Stephen F. Jencks, M.D (2009): March, 2010. Key Solutions for Decreasing Hospital Readmission http://www. Am health care.com/News, P.p. 123-125.

27. Thompson L, (2004): Disease management program: improving health while reducing costs. Washington, DC: Center on an Aging Society, Pp., 160- 164 http:// hpi. Georgetown. edu/ aging society/ pub htm/ management/ management.htm/. Accessed June 29, 2007.

28. Torhild Heggested, June, (2002): Do hospital length of stay and staffing ratio affect elderly patient's risk of readmission? Journal of General Internal Medicine.28 (13).

29. Weiss man J, Stern, R. (1999): The impact of patient's socioeconomic status and other social factors on readmission. Community- Dwelling Medicare 60 (1), P.p. 22-23

30. Williams, M.D, (2009): Study finds surprisingly high rate of patients' readmission to hospital within month. April, (2009)-http: //www physorg.com/news, P.p. 222-230.

31. Winslow E., (2001): Patients education Materials. American Journal of Nursing; October, 101 (10).P.p. 33-38. 